\title{
Movimentos na produção de políticas curriculares do estado do Rio de Janeiro: pensando a qualidade a partir das escolas
}

\author{
Alexandra Garcia \\ Graça Reis \\ Patrícia Baroni
}

\section{Resumo}

Com o objetivo de mostrar a influência de processos e interesses de centralização curricular e problematizar premissas políticas referentes às questões de trabalho e autonomia docentes, diferença, diversidade e contradições, apresentase um relato sobre a análise e contextualização do Documento curricular do estado do Rio de Janeiro, assim intitulado na versão preliminar, e aprovado como Documento de orientação curricular. A abordagem metodológica utiliza a narrativa e a análise das etapas do plano de ação como processo político democrático e coletivo, mobilizado por entidades educacionais e professores da educação básica. Os resultados evidenciam as pressões e as disputas durante o debate e as reconfigurações curriculares, pautando a defesa da democracia e da escola cidadã como perspectiva teórica e compromisso político do pensamento curricular.

Palavras-chave: documento curricular; estado do Rio de Janeiro; orientação curricular; políticas curriculares. 


\section{Abstract \\ Movements in the production of curricular policies for the State of Rio de Janeiro: quality coming from schools}

This article strives to show the influence of curricular centralization processes and interests, as well as to problematize the political premises regarding the issues of teaching work and autonomy, difference, diversity, and contradictions. In honor of that effort, it is presented a report on the analysis and contextualization of the Documento curricular do estado do Rio de Janeiro (Curricular Document of the State of Rio de Janeiro), thus referred in its first print, later approved as Documento de orientação curricular (Document for Curricular Guidance). The methodological approach employs the narrative and the analysis of the stages of the action plan as a democratic and collective political process, mobilized by educational entities and basic education teachers. The results reveal the pressures and disputes in the course of the debate and the curricular reconfigurations, guiding the defense of democracy and the citizen school as a theoretical perspective and political commitment of curricular thinking

Keywords: curricular document; curricular orientation; curriculum policies; State of Rio de Janeiro.

\section{Resumen \\ Movimientos en la producción de políticas curriculares del estado de Río de Janeiro: pensando la calidad desde las escuelas}

Con el fin de mostrar la influencia de los procesos e intereses de centralización curricular y problematizar premisas políticas sobre temas laborales y autonomía docentes, diferencia, diversidad y contradicciones, se presenta un informe sobre el análisis y contextualización del Documento curricular del estado de Río de Janeiro, así titulado en la versión preliminar, y aprobado como Documento de orientación curricular. El enfoque metodológico utiliza la narrativa y el análisis de las etapas del plan de acción como un proceso político democrático y colectivo, movilizado por entidades educativas y profesores de la educación básica. Los resultados muestran las presiones y disputas durante el debate y las reconfiguraciones curriculares, pautando la defensa de la democracia y la escuela ciudadana como perspectiva teórica y compromiso político del pensamiento curricular.

Palabras clave: documento curricular; estado de Rio de Janeiro; orientación curricular; políticas curriculares. 


\section{Introdução}

Pensar as práticaspolíticas ${ }^{1}$ curriculares a partir da problematização dos conhecimentos escolares e da função social da instituição escola, tendo em vista uma educação de qualidade social referenciada, é o que move as discussões apresentadas neste artigo. Essa é uma questão que se coloca com o descompasso muitas vezes observado entre as produções cotidianas das escolas e os documentos de políticas curriculares destinados a elas. Não é raro que os documentos que tratam de políticas voltadas para os currículos nas escolas desconsiderem que é no cotidiano das escolas e do fazer docente que os currículos são efetivamente produzidos, e que isso indica a necessidade de diálogo entre o contexto em que esses documentos são elaborados e os contextos escolares.

O texto toma por base um processo vivido no estado do Rio de Janeiro em torno dessa questão maior que mobilizou uma articulação que podemos considerar constitutiva de um momento histórico na formulação e disputa política. Nesse contexto, abordamos a discussão em torno da produção dos currículos e das políticas públicas referentes aos anos iniciais do ensino fundamental, na perspectiva expressa em parecer elaborado por professores-pesquisadores da educação básica que integraram a equipe que analisou o texto preliminar, intitulado Documento Curricular do Estado do Rio de Janeiro (Dcerj). Nesse sentido, situamos a discussão considerando a relevância da articulação estabelecida na condução do processo entre o Conselho Estadual de Educação (CEE-RJ) e o Fórum Estadual de Educação do Estado do Rio de Janeiro (Feerj). O encaminhamento integrou entidades científicas participantes do Feerj, professores da educação básica e universidades na avaliação, influenciando a produção de uma política pública.

O movimento de análise e produção de um parecer acerca do documento que envolveu diferentes representações trouxe alguns elementos para pensarmos a relevância da articulação entre tais entes na discussão e na formulação de princípios e propostas destinados às políticas públicas. Esse movimento pode ser dividido em diferentes ações e momentos, a saber:

- a composição do Grupo Coordenador que assessorou o CEE-RJ na análise preliminar do documento e na proposição de um plano e de um cronograma de ações para discussão com representantes das seguintes entidades:

- Associação de Pós-Graduação e Pesquisa em Educação (Anped);

- Associação Nacional pela Formação dos Profissionais da Educação (Anfope);

- Associação Brasileira de Currículo (ABdC);

- Associação Nacional de Política e Administração da Educação (Anpae); e

- Fórum Estadual de Educação do Estado do Rio de Janeiro (Feerj).

\footnotetext{
${ }^{1}$ O termo utiliza um recurso estilístico próprio do campo das pesquisas com os cotidianos, que recorre ao neologismo, juntando palavras para produzir sentidos outros, diferentemente da dicotomia sugerida pela grafia das palavras em separado. No caso desse termo em especial, o recurso, também empregado em outros termos ao longo do texto, implica pensar que toda prática é política e que toda política é também uma prática.
} 
- elaboração de uma Carta de Princípios (2019) - reafirmando a Carta do Rio (2018) - para orientar a análise do documento em sua versão preliminar;

- análise do documento por especialistas-professores ligados às entidades de pesquisa de diferentes áreas, níveis e modalidades da educação básica, tendo como perfil prioritário a experiência docente e as pesquisas no "chão das escolas";

- seminário público para a apresentação das análises do grupo de especialistas ao CEE-RJ;

- audiências públicas foram realizadas em Niterói (21 de maio), Volta Redonda (23 de maio), Macaé (29 de maio) e Rio de Janeiro (capital, na Universidade do Estado do Rio de Janeiro, em 6 de junho); os debates, nessas audiências, foram subsidiados pelo acesso prévio ao Dcerj e às contribuições críticas de especialistas por meio de link aberto, socializado pela circulação dos convites às audiências em mídias sociais; ${ }^{2}$

- consolidação das análises e contribuições críticas do Grupo Coordenador e o encaminhamento ao CEE-RJ, com vistas à apreciação do documento.

Esse conjunto de ações permitiu ampliar a participação pública na discussão e melhor subsidiar a emissão de um parecer sobre o documento pelo CEE-RJ, que, ao fazê-lo, indicou a necessidade de sua revisão pelos redatores originais.

Um dos aspectos relacionados à problematização da concepção de currículo no texto preliminar, herdeira de uma visão restrita e instrumental presente na Base Nacional Comum Curricular (BNCC), se refere ao título Documento curricular do estado do Rio de Janeiro, por denotar lista de conteúdos ou grade de disciplinas. Essa compreensão, bastante comum aos que entendem currículo como uma questão técnica, e até mesmo prescritiva, também, expressa um entendimento do que seja o conhecimento e como ele é produzido. Após o movimento aqui narrado, o texto foi aprovado como Documento de orientação curricular do estado do Rio de Janeiro (DOC-RJ), em 8 de outubro de 2019, estabelecendo princípios e referências para os currículos das instituições de natureza pública ou privada que fazem parte do sistema estadual da educação básica no Rio de Janeiro (CEE. Deliberação nº 373, 2019).

\section{Contexto das discussões sobre centralização curricular}

Todo o movimento que enfocamos aqui é arrolado no âmbito de processos mais amplos, que o antecedem e que se relacionam às discussões, pesquisas e ações

\footnotetext{
2 Segundo o CEE-RJ, nelas estiveram representados os municípios de: Angra dos Reis, Armação dos Búzios, Cabo Frio, Casimiro de Abreu, Conceição de Macabu, Duas Barras, Itatiaia, Macaé, Magé, Maricá, Mendes, Miguel Pereira, Nilópolis, Niterói, Nova Friburgo, Paraíba do Sul, Paraty, Paty do Alferes, Pinheiral, Piraí, Quatis, Queimados, Quissamã, Resende, Rio Claro, Rio das Ostras, Rio de Janeiro, Santo Antônio de Pádua, São Gonçalo, Sapucaia, Saquarema, Seropédica, Silva Jardim, Tanguá, Teresópolis, Três Rios, Vassouras e Volta Redonda (Metodologia..., 2019, p. 12).
} 
empreendidas por pesquisadores, entidades da área, professores e organizações de classe do magistério em torno da problematização do processo de centralização curricular configurado pela BNCC. Quando pensamos em uma educação de qualidade social referenciada, é importante ressaltar que os movimentos e as discussões em torno da problematização de uma base nacional e das implicações de processos de centralização curricular tiveram início em 2014 e se intensificaram com as ações articuladas pelas entidades de pesquisa na área, sobretudo a Anped, a ABdC e a Anfope, entre outras, e a participação em audiências públicas organizadas pelo Ministério da Educação (MEC), nos debates em universidades, junto às redes municipais e estaduais, nas escolas e em diversos eventos voltados aos professores da educação básica e à comunidade acadêmica. Tais movimentos e os principais aspectos problematizados em pesquisas, em particular no campo do currículo, podem ser conhecidos por meio da série de dossiês sobre o tema e suas interfaces, organizados pela ABdC.

Mesmo diante do alerta de pesquisadores e de uma forte oposição dos professores, o encontro de aspectos relacionados a uma visão universalizante de conhecimento se inscreve de maneira subliminar no entendimento de conhecimento escolar. A compreensão eminentemente técnica e objetificante de currículo e conhecimento, além de interesses políticos e econômicos externos aos sujeitos e internos aos setores conservadores e a um nicho do mercado, convergiram para a promulgação da BNCC em 2017. Em 2018, o MEC estabeleceu que os estados realizassem a adequação de suas diretrizes curriculares à Base (Brasil. MEC, 2017).

O CEE-RJ recebeu o Dcerj, elaborado pela colaboração entre a União Nacional dos Dirigentes Municipais de Educação do Rio de Janeiro (Undime-RJ), a Secretaria de Estado de Educação (Seeduc-RJ) e a União Nacional dos Conselhos Municipais de Educação do Rio de Janeiro (UNCME-RJ).

\begin{abstract}
Com a intenção de implementar uma proposta metodológica não verticalizada, a Conselheira Presidente e o Conselheiro Relator apresentaram ao Conselho Pleno do CEE-RJ uma forma efetivamente participativa de trabalho, horizontalizada, que se iniciou por ouvir as representações das Entidades Científicas Educacionais do Rio de Janeiro e o Fórum Estadual de Educação para, coletivamente, organizar um plano de ação que envolvesse o estabelecimento de categorias de análise, a definição de dinâmica para audiências públicas, a indicação de reuniões técnicas com especialistas, entre outras estratégias de ação, constituindo um Grupo Coordenador do trabalho. (Metodologia..., 2019, p. 10).
\end{abstract}

Diante desse encaminhamento, representantes de algumas entidades ligadas à pesquisa em educação, currículo e formação de professores, participantes do Feerj e representantes desse fórum que compunham o Grupo Coordenador realizaram um estudo prévio do documento. Esse estudo fez parte de um conjunto de ações propostas e organizadas pelo Grupo Coordenador, constituído pela parceria entre o CEE-RJ e o Feerj para apoiar a análise do Dcerj. Os encaminhamentos devem ser compreendidos no bojo do caráter democrático da condução adotada pelo CEE-RJ, que justifica suas ações na apresentação do relatório resultante da apreciação do Dcerj feita pelo Conselho e das contribuições críticas fruto do conjunto de ações encaminhadas. 
Cabe destacar que, no processo encaminhado no âmbito do plano de ações, as entidades educacionais ficaram responsáveis pela indicação de três especialistas por área de conhecimento presente na proposta preliminar do documento curricular. Em uma primeira análise, realizada pelo Grupo Coordenador, observou-se que havia no documento a omissão de importantes áreas e que a presença de especialistas das áreas omitidas se fazia necessária na análise a ser encaminhada. Os profissionais indicados deveriam ter experiência docente em escolas (das redes pública e privada) e serem afiliados a associações ou sociedades científicas de sua área de conhecimento.

O estudo identificou questões diversas, que evidenciaram a necessidade de uma análise mais aprofundada do documento preliminar, entre as quais se destacavam: a concepção de currículo subjacente ao documento; a compreensão da docência e do papel do professor diante do currículo; questões relacionadas às legislações educacionais vigentes e às diferentes áreas de conhecimento; os níveis e as modalidades da educação básica.

O processo de adequação dos documentos estaduais e municipais de referência curricular tem sua origem na promulgação da BNCC, que segue e aprofunda caminhos de centralização curricular vivenciados no Brasil há algumas décadas. A discussão sobre normatizações para os currículos se colocou em distintos momentos de nossa história. Desde a década de 1980, notamos uma tendência para a unificação. Essa demarcação temporal nos faz concluir que a busca por normatização não é nova no Brasil e sempre envolveu processos de disputas políticas, mais ou menos intensas, e a participação em maior ou menor grau de entidades e fóruns do campo da educação. Como exemplificação, tivemos os Guias Curriculares, os Parâmetros Curriculares e as Diretrizes Curriculares Nacionais.

Com relação a essa questão, precisamos contextualizar as recentes discussões sobre as políticas voltadas para os currículos da educação básica em face das críticas produzidas por pesquisas nesse campo, que apontam os reflexos de modelos monoculturais, entre outros aspectos, atuando sobre a definição de conhecimentos considerados universalmente relevantes para o currículo. Esse aspecto veio se intensificando nos textos de documentos oficiais e mesmo no encaminhamento dos debates sobre as políticas nacionais nas esferas de governo, especialmente na federal. As tendências materializadas pela BNCC mostram que a intensificação da centralização curricular foi sendo articulada com mecanismos políticos de controle, sejam eles avaliativos ou ligados à formação dos professores da educação básica.

Outra questão predominante que merece ser problematizada está relacionada à ideia expressa pelo título original - Documento curricular -, que revela um entendimento de que o texto de um documento de orientação curricular seria o currículo propriamente dito. Nesse sentido, vale ressaltar a relevância, no que tange à produção curricular mobilizada por professores e escolas cotidianamente, de perceber o currículo como processo de produção permanente, que apenas existe como aquilo que resulta desta ou simplesmente é essa produção. Ao mesmo tempo, é preciso considerar que os textos dos documentos expressam intencionalidades e sentidos políticos para a educação, bem como concepções de docência e escola relacionadas a esses sentidos. Por isso, torna-se importante analisar os textos e os 
movimentos envolvidos em sua produção, na medida em que são parte constituinte e constitutiva de lutas mais amplas pela educação e pelos sentidos de qualidade e de educação a ela relacionados e pelos quais lutamos para dar visibilidade aos saberes e fazeres docentes envolvidos na disputa e na produção curricular efetiva. Assim, os textos de documentos oficiais precisam ser considerados a fim de garantir as condições mais amplas para que a educação se realize e, se necessário para tanto, respeitar a autonomia docente e valorizar a profissão. Esses são aspectos expressos na Lei de Diretrizes e Bases da Educação Nacional (LDB) e no Plano Nacional de Educação (PNE), reforçados e retomados pela Carta do Rio (2018).

Os tensionamentos que se inscrevem na discussão relativa a um documento voltado para a orientação curricular do sistema de ensino estadual têm sua origem na tendência centralizadora sobre os currículos, que se intensificou nos últimos anos. Olhando para tal tendência e para os tensionamentos, podemos melhor explicar as forças envolvidas na produção das políticas:

Fruto de um esvaziamento nos sentidos de educação, em particular da educação escolarizada, as políticas educativas propostas pelos governos em diferentes países há mais de duas décadas e boa parte dos discursos sociais mostram-se fortemente identificados com o economicismo. Quando pensamos a partir de nossas pesquisas nas formas e práticas de resistências desenvolvidas pelas escolas públicas, sobretudo por seus professores, [podemos perceber os modos como] as escolas e professores estão sobrevivendo e resistindo às políticas de esvaziamento do público e aos sentidos hegemônicos que afetam a educação na atualidade. (Garcia; Rodrigues, 2019, p. 7).

Quando nos debruçamos sobre esse histórico, no qual o processo vivido no estado do Rio de Janeiro se insere, somos convocados a discutir a lógica de centralização curricular que vem se difundindo via proposição da BNCC para a educação básica, tendo em vista a problematização dos sentidos a que se atrela a ideia de qualidade em questão:

Com contornos mais delineados a partir da década de 90 e tons mais intensos a cada ano transcorrido desde então, os discursos sobre a qualidade na/ da educação tornaram-se o fim e a justificativa que dispensa argumentos melhor desenvolvidos, como por efeito ocorre com qualquer expressão que se transmute em um jargão. Camuflam, por assim dizer, as disputas pelos sentidos de qualidade e de educação servindo, portanto, ao uso desde propostas políticas identificadas com o economicismo em diferentes níveis e instâncias do poder público até projetos de intervenção e interdição do que pode ou não a escola ensinar. Em qualquer um dos casos, e não é fenômeno recente, o controle sobre a docência como condição, consequência ou prática-política de vigilância e padronização ganha força. (Garcia; Rodrigues, 2019, p. 3).

É nesse cenário que o relato dos movimentos de disputa e a produção de práticaspolíticas curriculares postos em evidência chamam a atenção para o debate relacionado ao processo de centralização dos currículos. Ao trazer para a discussão os apontamentos e as análises sobre os anos iniciais do ensino fundamental, temos a possibilidade de expor questões e implicações expressas nas minúcias dos aspectos apontados pelos professores desse grupo de trabalho ao pensarmos as referências para os currículos escolares. 


\section{As práticaspolíticas: produção de políticas como ações cotidianas}

A quem cabe a elaboração e a implementação de políticas curriculares? Há um discurso impregnado no imaginário social de que há aqueles que fazem políticas e aqueles que as implementam (ou deveriam). Tal discurso se inscreve numa concepção ainda mais ampla de que aos educadores compete apenas realizar as ações propostas por "instâncias hierarquicamente superiores", ou seja, nessa lógica, o fazer e o pensar estão em campos separados. De acordo com ela, subtrai-se das relações a sua complexidade, como se a vida fosse estanque, separada em quadrados em que cada sujeito ocupa o seu espaço sem atravessar as fronteiras que o delimitam. Segundo Morin (2003), fomos ensinados a isolar: os objetos do meio ambiente, as disciplinas das relações entre elas. Dessa forma, reduzimos o que, a priori, é complexo ao simples, isto é, somos ensinados a decompor, a eliminar a desordem e as contradições. Nesse mundo sem complexidade, no imaginário dos sujeitos que separam o pensar do fazer, "criamos" aqueles que pensam as políticas de educação, muitas vezes numa visão determinista, mecanicista, quantitativa, formalista e em forma de árvore,

[...] o que pressupõe um caminho obrigatório, único, linear e hierarquizado. É a partir desta ideia que se entende que se está melhor, se sabe mais, quando atingindo o cimo, chegamos às indispensáveis folhas (que nos permitem respirar melhor), às lindas flores (que nos permitem poetizar a vida) e aos frutos saborosos (que não nos deixam morrer de fome). (Alves, 2000, p. 113).

Desse modo, abarcando uma perspectiva predominantemente técnica e, em consequência, prescritiva das políticas curriculares, a formulação destas acaba por excluir a subjetividade, a afetividade, a liberdade e a criação. Forma-se, assim, um espaçotempo constituído por quadrados imaginários e estanques, em que as políticas são elaboradas no interior de gabinetes fechados, e os professores são os responsáveis pela sua execução. Nessa relação, sempre de forma vertical, tal como na metáfora da árvore, "os problemas não resolvidos da realidade são sempre 'culpa' de quem não entende ou não sabe usar as ideias e determinações, sempre bem pensadas" (Oliveira, 2013, p. 378), ou seja, dos professores.

Os estudos com os cotidianos, nossa opção epistemológicateóricapolítica, têm nos ensinado a impossibilidade dessa falta de circulação e dessa relação vertical, pois

as escolas vivem permanentemente esses embates, são organismos vivos que pulsam, ou seja, há vida dentrofora (Alves, 2010) das escolas, independente daquilo que se espera que elas sejam dentro de seus muros físicos. Alunos, professores e todos aqueles que ali circulam produzem cotidianamente relações e conflitos que muito certamente não são sempre os mesmos e nem se dão sempre da mesma forma. Digo com isso que esses sujeitos criam/praticam relações e políticas em seu cotidiano e vão defendê-las ou não, de acordo com o que a ocasião permite e possibilita. (Reis, 2014, p. 37).

Nesse sentido, os movimentos de produção de políticas curriculares de qualidade são perpassados pela presença e pela interferência de sujeitos plurais: de todos que criam currículos nos cotidianos, seja no âmbito das vivências do "chão da 
escola", seja no da macropolítica, seja no da pesquisa científica, seja no das intersecções desses espaçostempos. Daí nosso interesse em acompanhar e relatar os movimentos de criação do DOC-RJ, não apenas por termos participado diretamente desses movimentos, mas também por compreendermos que a diversidade é constitutiva de qualidade.

Somos sujeitos e fazemos parte de uma rede em que poderes, saberes, afetos e fazeres circulam o tempo todo, mostrando a impossibilidade de separar o pensar do fazer. Entendemos, assim, que dissociar políticas e práticas como se fossem campos diferenciados, com seus respectivos atores em cada lado do processo, é uma perspectiva que tenta deixar de fora a riqueza da vida real nas/das escolas.

Stephen Ball (2001) se refere à produção dessas políticas como um "ciclo de políticas", ou seja, ele usa a circularidade para compreender como políticas e práticas se influenciam mutuamente, destacando a natureza complexa e controversa da política educacional e enfatizando os processos micropolíticos e a ação dos profissionais que lidam com as políticas no nível local. Cada um desses contextos apresenta arenas, lugares e grupos de interesse, e cada um deles envolve disputas e embates. Com a imagem da circularidade, o autor afirma que políticas oficiais e práticas desenvolvidas nas escolas interagem e, dessa forma, determinam-se mutuamente de forma dinâmica e flexível.

Concordando com Ball acerca da impossibilidade de separação entre política e prática, usamos a metáfora da rede para pensar tal movimento, porque

[...] nela é possível estabelecer um sem número de percursos para se ir de um ponto a outro ponto, complexificando as lógicas de compreensão dos múltiplos espaçostempos do viver humano, exigindo que esses sejam percebidos como não completamente ordenados, [...], porque fruto de múltiplas e diferentes práticas, em permanente mudança. (Lefebvre, 1983, p. 35-36).

Fazemos esse movimento porque compreendemos que as práticaspolíticas interagem horizontalmente envolvendo todos os que fazempensam a educação, de forma que documentos oficiais, professores e todos os outros dentrofora das escolas dialogam com essas políticas "mais ou menos intensamente, em virtude do seu poder de intervenção" (Oliveira, 2013, p. 378). Edgar Morin (1995, p. 182), em seus estudos acerca do complexus, nos alerta sobre a impossibilidade de sabermos, nos processos sociais, quem é produto e quem é produtor: "o processo social é um círculo produtivo ininterrupto no qual, de algum modo, os produtos são necessários à produção daquilo que os produz", ou seja, não há como determinar a partir de que essas práticas políticas são produzidas.

Aqui é importante (re)afirmarmos nossa escolha pela pesquisa nosdoscom os cotidianos, que exige estarmos atentas a todos os movimentos, dizeres e fazeres docentes, isto é, nossa caça por aquilo que, a princípio, é irrelevante nos leva a olhar para a discussão, os apontamentos e as análises realizadas, tentando perceber o que podem nos contar sobre a elaboração dessas políticas e seus embates.

Ao acompanharmos o processo de elaboração do relatório avaliativo do Dcerj, foi possível perceber que as discussões e os apontamentos, feitos pelo grupo de especialistas, em especial pelo grupo de trabalho de anos iniciais do ensino 
fundamental, nos levam a entender que as práticaspolíticas são múltiplas e resultado dos embates travados entre os diferentes grupos de profissionais da educação e os "usuários" do sistema público. De acordo com essa ideia, compreendemos, então, que algumas se tornam hegemônicas em função do lugar que cada sujeito, com suas crenças, suas ideias e ideais, ocupa. Tomamos emprestada de Santos (1995) a ideia de arquipélago de subjetividades para pensar que também as políticas públicas se movimentam nessa mesma relação, e o embate ora acentua mais determinada concepção de mundo, ora acentua outra, nesse caso, de acordo com o tempo e o espaço ocupados pelos gestores da educação no município. Segundo o autor:

Somos um arquipélago de subjetividades que se combinam diferentemente sob múltiplas circunstâncias pessoais e colectivas. Somos de manhã cedo privilegiadamente membros de família, durante o dia de trabalho somos classe, lemos o jornal como indivíduos e assistimos ao jogo de futebol da equipe nacional como nação. (Santos, 1995, p. 107).

De acordo com essa lógica, são tornadas hegemônicas e chamadas políticas nacionais/estaduais/municipais aquelas que fazem parte dos documentos oficiais do Estado. Nesses documentos encontramos diversas concepções de educação, com prevalência daquelas que expressam os grupos politicamente hegemônicos, e também são perceptíveis muitos dos embates travados durante as suas formulações.

Contudo, subvertendo a lógica posta e naturalizada pelo imaginário social, o CEE-RJ, ao acessar a política curricular concebida por um grupo restrito, compreendeu que era preciso pluralizar os sujeitos da formulação. Os especialistas convidados a participar do processo destacaram que corroboravam essa compreensão, afirmando que o ofício docente qualificado depende da possibilidade de autoria dos professores. Assim sendo, o texto introdutório das contribuições críticas dos especialistas destaca que:

A análise do referido documento é acompanhada pela leitura das atuais conjunturas políticas e sociais, considerando-se a complexidade de intenções e motivações que se formam como cenário para decisões tendenciosamente mais excludentes e hegemônicas em educação. Como professores e gestores educacionais no Estado do Rio de Janeiro, assumimos o compromisso de zelar pelo direito à diversidade de estudantes, professores e comunidades, de maneira que isto se reflita no documento curricular em análise. Acreditamos também na profissão docente qualificada e legitimada em seus direitos de escolhas pedagógicas, desde que sejam sempre garantidas as práticas INCLUSIVAS, CONTEXTUAIS e AUTORAIS. (CEE-RJ, 2019, p. 23).

A seguir, apresentamos alguns dados que compõem o relatório avaliativo dos especialistas, destacando as questões apontadas pelas professoras e gestoras que compuseram o grupo de trabalho de anos iniciais do ensino fundamental. A produção da equipe chama a atenção para a necessária escuta de quem vivencia o "chão da escola" nas discussões e formulações curriculares. 


\title{
Experiência de autoria docente na formulação de políticas curriculares: o grupo de especialistas de anos iniciais
}

Nesta parte do artigo, implica destacar uma questão também naturalizada no imaginário social: o problema da autoria que, segundo Santos (2019, p. 87), "referese ao fato de a maior parte dos conhecimentos que têm origem em lutas sociais serem coletivos ou funcionarem como tal".

Com essa proposição, demarcamos uma perspectiva que não concebe autoria como um conceito que exige originalidade individualista e possessiva. Entendemos, ao demandar que professores sejam autores de suas práticaspolíticas, que tal autoria se inscreve como luta coletiva e cotidiana. Conforme nos explica Santos (2019, p. 88),

\begin{abstract}
os conhecimentos irrompem, muitas vezes de formas surpreendentes, em momentos de ação ou de reflexão, momentos que são especialmente tensos devido aos riscos e desafios em causa. Ou então trata-se de memórias coletivas (conhecimentos tácitos, latentes) que muito precedem os contextos da vida e da luta do presente. (...) A maior parte dos conhecimentos que surgem da luta são coletivos ou funcionam como tal. Muitas vezes os conhecimentos mais cruciais não têm autores. São eles mesmos autores.
\end{abstract}

As questões apresentadas a seguir têm como eixo estruturante a proposição que transbordou na escrita do relatório avaliativo: professores precisam ser autores. Tal ideia confirma uma luta coletiva pela escuta desses sujeitos na elaboração das políticas educacionais. O texto introdutório do documento destaca que a fratura existente entre aqueles que formulam e aqueles que executam as políticas curriculares, bem como a impossibilidade de leitura crítica por parte destes, tem como consequência a promoção de desigualdades sociais. Isso porque acolher a escuta das escolas e das lutas docentes implica necessariamente a assunção de um posicionamento político que concerne à política educacional. De acordo com o relatório,

Entendemos que precisa estar sinalizado no texto introdutório, logo de início, a leitura crítica necessária a toda política pública educacional, e que o Estado do Rio de Janeiro precisa se colocar no movimento de resistência contra qualquer imposição que deságue em práticas unificadas e descontextualizadas que venham a aumentar ainda mais os abismos entre os mais ricos e os mais pobres. Esta discussão de classes cabe aqui porque, de forma muito clara, as políticas de formação docente que acompanham a divulgação da BNCC são embasadas em discurso claramente preconceituoso que nega as contribuições mais atuais e democráticas em educação, privilegiando concepções educacionais já superadas, como por exemplo, a discussão em torno da instrução fônica de ensino na alfabetização, que insistentemente aparece nas formações atuais de professores, conforme pode ser identificado também no Decreto 9.765/2019. Portanto, a BNCC, como base legal, não inviabiliza a leitura crítica do documento produzido pelo Estado, como garantia de voz e vez aos tantos e diversos modos de interação com a cultura escolar com os quais lidamos todos os dias nas escolas. Ao contrário, marca um respeitoso "lugar de fala" de toda uma comunidade docente que, ao longo de várias décadas, investe em estudos e formações pela e para a diversidade de modos de ser e estar no mundo, de interagir com a escola e de aprender. (CEE-RJ, 2019, p. 23). 
O Grupo de Trabalho que se dedicou à análise das proposições para os anos iniciais do ensino fundamental, no Dcerj, foi formado por professoras da educação básica e do ensino superior, de diferentes sistemas de ensino. ${ }^{3}$ Após diversas reuniões, o grupo demarcou oito problematizações acerca da escrita preliminar enviada:

1) finalidade do documento;

2) ausência de diálogo do documento com as escolas;

3) invisibilidade das diferentes modalidades que oferecem anos iniciais do ensino fundamental;

4) descontinuidade entre a educação infantil e o ensino fundamental;

5) despolitização do texto;

6) desatualização conceitual;

7) necessária revisão da legislação; e

8) inclusão de fragmentos desconexos identificados em outras produções.

Sobre a primeira problematização - finalidade do documento - as professoras do grupo de trabalho ressaltaram que há no corpo do texto finalidades diversas e contraditórias:

ora se trata de um documento que "estrutura o currículo" do Estado do Rio de Janeiro; ora, de um documento que se anuncia como uma leitura da Base Curricular Nacional, constituindo-se como uma Base Curricular Estadual; ora o documento é qualificado como implementador de diretrizes curriculares para o estado; ora no documento consta que sua finalidade não é prescritiva. (CEE-RJ, 2019, p. 56).

$\mathrm{Na}$ análise, faz-se importante mencionar que cada uma das finalidades identificadas pelas professoras é atravessada por uma concepção de currículo. O obscurantismo quanto à concepção adotada pelo documento e, por vezes, a coexistência de diferentes concepções de currículo refletem a incoerência presente na versão preliminar. Contudo, salientamos que tal incoerência quanto às concepções de currículo existe inclusive nos documentos nacionais, os quais, supõe-se, referenciam as políticas curriculares dos estados e municípios. Assim, o grupo de trabalho destacou a necessidade de o documento ser apresentado com a finalidade de "orientação curricular" e a proposição de se levar em conta que currículo se produz cotidianamente, em cada espaço educativo, e com respeito às concepções pedagógicas de cada docente.

Sobre a segunda problematização - ausência de diálogo do documento com as escolas -, as professoras do grupo de trabalho de anos iniciais apontaram que o corpo do texto possui muitos fragmentos com a enunciação "o professor deve...", de modo que o documento define o lugar dos docentes, reduzido à subserviência da prescrição. O fato de o documento preliminar possuir 456 páginas, ou seja, ser demasiadamente extenso, e se distanciar do vivido, do praticado nas escolas

\footnotetext{
${ }^{3}$ Compuseram o Grupo de Trabalho de Anos Iniciais do Ensino Fundamental as professoras Patrícia Baroni, Claudia Andrade, Ana Paula Batalha, Paula Cid, Claudia Gomes, Regina Macedo e Elaine Constant.
} 
fluminenses, permite afirmar que o texto não conversa com as escolas, com suas demandas e com suas concepções de currículo. De acordo com as professoras que o analisaram, o texto prescreve o que e de que forma os professores devem ensinar, tendo como referencial uma escrita incoerente e não dialógica.

Quanto à terceira problematização - invisibilidade das diferentes modalidades que oferecem anos iniciais do ensino fundamental -, foi observado que o termo "criança" é utilizado no texto para tratar de quem faz jus ao ensino fundamental. Dessa forma, são invisibilizadas todas as demais modalidades de ensino. Ainda que o texto seja cuidadoso ao informar aos seus leitores que o ensino fundamental é oferecido no estado do Rio de Janeiro nas diferentes modalidades de ensino Educação do Campo, Educação Especial, Educação de Jovens e Adultos, Educação de Pessoas em Sistema de Privação de Liberdade etc. -, ao longo do documento, não é feita nenhuma menção a essas modalidades.

A análise da quarta problematização - descontinuidade entre a educação infantil e o ensino fundamental - identificou que a educação básica é apresentada em uma perspectiva fragmentada, desconexa e gradual. Nessa perspectiva, a educação infantil e o ensino fundamental são apresentados como "etapas" da educação básica. Em muitos momentos, o texto trata de "aprendizagens progressivas" ao tentar esclarecer a questão. Não foi possível perceber interseções que permitam aos estudantes viver a educação como processo; nem nos campos de experiência da educação infantil, nem nas habilidades e competências dos anos iniciais do ensino fundamental encontramos interseções. As professoras que compuseram o grupo de trabalho destacaram que

o conjunto do texto afirma a educação infantil enquanto o lugar da brincadeira, o lugar das interações. Quando chega ao ensino fundamental, a escola é apresentada como o lugar da alfabetização, do desenvolvimento de habilidades e de competências relacionadas a conteúdos das chamadas aprendizagens essenciais. (CEE-RJ, 2019, p. 57).

Sobre a quinta problematização - despolitização do texto - as professoras do grupo de trabalho ressaltaram que o documento preliminar não apresenta eixos que permitam a realização de um trabalho interdisciplinar. De acordo com elas, as áreas são apresentadas como núcleos isolados, cujos saberes próprios se prestam somente à aplicação. A análise afirma que o isolamento dos conteúdos favorece sua despolitização. Ao serem isolados, os conteúdos impossibilitam a reflexão à luz de outros saberes. Sobre isso, o grupo de trabalho diz:

Nós, professores e professoras, alunos e alunas, todos os dias problematizamos conteúdos, construímos e descontruímos teses, relacionamos o praticadopensado aos debates mais globais de nossa sociedade, bem como identificamos as especificidades dos municípios onde atuamos, das comunidades das quais fazemos parte, das questões que se mostram presentes em cada unidade escolar. Mesmo assim, o documento despolitizou as disciplinas, desconsiderou a potência de reflexão e ação de alunos e de alunas do Estado do Rio de Janeiro. (CEE-RJ, 2019, p. 58).

Quanto à sexta problematização - desatualização conceitual -, o grupo de trabalho sugeriu que o documento fosse revisto, tendo como referência os debates 
acadêmicos atuais e as experiências vividas pelos professores do estado. Como exemplos, destacaram o uso no documento das expressões "educação prisional" e "educação socioeducativa".

Quanto à sétima problematização - a necessária revisão da legislação - o grupo salientou que o documento concebe como "arcabouço legal que fundamenta a implementação do ensino fundamental de nove anos" a Emenda Constitucional n 59/2009. Tal emenda modificou a Constituição Federal em seus artigos 208, 211, 212 e 214, ampliando a obrigatoriedade apenas do ensino fundamental para toda a educação básica a partir dos 4 anos de idade. É válido informar que o ensino fundamental de nove anos passou a vigorar com a aprovação da Lei no 11.274 , de 2 de fevereiro de 2006, modificando o texto da LDB.

Finalmente, sobre a última problematização - inclusão de fragmentos desconexos identificados em outras produções -, o grupo de trabalho das professoras especialistas ressaltou a ética como princípio necessário às práticas educativas e ao exercício do ofício docente. Cabe problematizar o modo como a produção de textos em documentos oficiais pode acabar em bricolagens que pouco contribuem para a relação entre os documentos e aquilo que efetivamente se produz nas escolas, em especial a possibilidade de refletirem a riqueza das produções e valorizarem a construção de propostas comuns locais.

O conjunto de problematizações do grupo de trabalho foi exposto durante o seminário de apresentação das considerações críticas dos especialistas acerca da versão preliminar do documento e compôs o relatório entregue à Secretaria Estadual de Educação para revisão.

\section{O que aprendemos com os movimentos: breves considerações sobre produções de políticas curriculares}

A revisão que resultou desse movimento trouxe, entre outras mudanças relevantes, a alteração no título do documento, conforme mencionamos. O acréscimo da palavra "orientação", onde anteriormente se lia Documento curricular somente, parece um detalhe sutil. No entanto, é um detalhe que permite o entendimento de que a produção curricular, de fato, está e se dá nas escolas. Na esteira dessa mudança, também se problematiza a lógica implícita de que um currículo seria definido por um texto e que ao professor caberia, tão somente, a sua execução. Problematizar esse entendimento na mudança do título significa também problematizar a centralização curricular expressa na ideia de que o currículo estaria dado pelo texto de um documento e, portanto, seria único.

Os aspectos problematizados pelo grupo de trabalho de anos iniciais vieram ao encontro das questões levantadas neste texto quanto aos condicionantes de uma educação de qualidade social referenciada, quando mostra a necessidade de que a redação do DOC-RJ se remeta à legislação vigente, de modo a respeitar conquistas históricas da educação. Também se destaca a preocupação com as políticas públicas e os documentos que as textualizem para que expressem coerência com os princípios políticos. 
Outra questão levantada pelas análises lembra a necessidade de que, nos processos de produção dos textos relacionados às políticas públicas, os professores sejam percebidos na autoria dos currículos e das práticaspolíticas que as escolas encaminham. Nesse sentido, entendemos que o movimento provocado na condução do conjunto de ações organizadas pelo Grupo Coordenador favoreceu evidenciar esse aspecto e mobilizar as contribuições dos saberes docentes, seja na problematização do documento original, seja nas questões apontadas em audiências públicas, seja na indicação de caminhos necessários às políticas. Quando o movimento ocorrido no estado do Rio de Janeiro, pelo conjunto de ações aqui tratadas, amplia a discussão em torno dos currículos e traz professores ligados à educação básica para analisar um texto preliminar relacionado à política envolvida na normatização dos currículos, chama a atenção para o lócus da discussão das práticaspolíticas curriculares vinculadas ao propósito da qualidade na educação. Isso porque é a participação da comunidade escolar nos processos de discussão e produção dos projetos político-pedagógicos que melhor pode expressar as lutas por qualidade na educação.

Ressalte-se também que, na versão preliminar do documento, a palavra "professor", referindo-se ao profissional na condição de autor, encontrava-se ausente no texto introdutório, sendo o professor mencionado apenas como responsável pela execução do que o documento prescrevia. Essa ausência, sintomática quando olhamos para a articulação dos processos de centralização curricular com avaliações externas, está associada a uma visão na contramão da valorização necessária da profissão docente quando pensamos em qualidade na educação.

A necessária observação do atendimento à diversidade em diferentes aspectos feita pelo grupo de trabalho, na segunda e na terceira problematização, principalmente, chama a atenção para a responsabilidade política que um texto como o DOC-RJ tem. A Carta de Princípios (2019) que orientou o processo de análise do Dcerj e que expressava elementos presentes tanto na LDB quanto na Carta do Rio (2018), sobretudo com relação ao cumprimento das metas do PNE e da Constituição Federal, remetia à observação do reconhecimento e da valorização das localidades e seus respectivos saberes, bem como à diversidade de ordens: étnica, política, social, cultural e mesmo quanto às ideias e concepções pedagógicas. Entendemos que as análises foram, nesse sentido, politicamente importantes para reafirmar o princípio da diversidade e da diferença, tão centrais à educação que se pretenda coerente com uma sociedade democrática. Esse certamente é um descritor de qualidade central.

O grupo de trabalho, nas diferentes áreas, trouxe apontamentos, críticas e ponderações que expressaram um estudo criterioso do documento preliminar. Ao longo dos trechos analisados, podemos perceber fortemente presente o reconhecimento daquilo que produzem as escolas e seus professores cotidianamente em suas práticas e currículos desenvolvidos. Também é marcante a preocupação em respeitar as diferenças pedagógicas, um fator crucial quando se pensa a autonomia docente. Sobretudo, é possível notarmos que a diversidade está presente nas preocupações com as políticas curriculares em relação a diferentes aspectos e situações, sejam culturais, linguísticas, locais etc. O conjunto das preocupações 
presentes na análise do documento nos remete ao entendimento mais amplo de que um documento que tem por finalidade a orientação curricular precisa, antes de tudo, garantir o atendimento às especificidades locais e dos sujeitos nos diferentes níveis e modalidades da educação básica, como preza a legislação educacional.

\section{Referências bibliográficas}

ALVES, N. Os romances das aulas. Movimento: Revista de Educação, Niterói, n. 2, p. 7-32, set. 2000 .

ALVES, N. A compreensão de políticas nas pesquisas com os cotidianos: para além dos processos de regulação. Educação \& Sociedade, Campinas, v. 31, n. 113, p. 1195-1212, out./dez. 2010.

BALL, S. Diretrizes políticas globais e relações políticas locais em educação. Currículo sem Fronteiras, [online], v. 1, n. 2, p. 99-116, jul./dez. 2001.

BRASIL. Constituição (1988). Constituição da República Federativa do Brasil. Brasília, DF: Câmara dos Deputados, 1988.

BRASIL. Decreto no 9.765, de 11 de abril de 2019. Institui a Política Nacional de Alfabetização. Disponível em: < http://www.planalto.gov.br/ccivil_03/_ato20192022/2019/decreto/D9765.htm>. Acesso em: 14 dez. 2020.

BRASIL. Emenda Constitucional n 59, de 11 de novembro de 2009. Acrescenta $\S 3^{\circ}$ ao art. 76 do Ato das Disposições Constitucionais Transitórias para reduzir, anualmente, a partir do exercício de 2009, o percentual da Desvinculação das Receitas da União incidente sobre os recursos destinados à manutenção e desenvolvimento do ensino de que trata o art. 212 da Constituição Federal, dá nova redação aos incisos I e VII do art. 208, de forma a prever a obrigatoriedade do ensino de quatro a dezessete anos e ampliar a abrangência dos programas suplementares para todas as etapas da educação básica, e dá nova redação ao § $4^{\circ}$ do art. 211 e ao $\S 3^{\circ}$ do art. 212 e ao caput do art. 214, com a inserção neste dispositivo de inciso VI. Diário Oficial da União, Brasília, DF, 12 nov. 2009. Seção 1, p. 8.

BRASIL. Lei n ${ }^{\circ} 11.274$, de 6 de fevereiro de 2006. Altera a redação dos arts. 29, 30, 32 e 87 da Lei no 9.394, de 20 de dezembro de 1996, que estabelece as diretrizes e bases da educação nacional, dispondo sobre a duração de 9 (nove) anos para o ensino fundamental, com matrícula obrigatória a partir dos 6 (seis) anos de idade. Diário Oficial da União, Brasília, DF, 7 fev. 2006. Seção 1, p. 1.

BRASIL. Ministério da Educação (MEC). Base Nacional Comum Curricular. Brasília: MEC, 2017. Disponível em: <http://basenacionalcomum.mec.gov.br/images/ BNCC_20dez_site.pdf>. Acesso em: 29 jun. 2020.

CARTA de princípios para subsidiar o Documento Curricular do Estado do Rio de Janeiro. In: CONSELHO ESTADUAL DE EDUCAÇÃO DO ESTADO DO RIO 
DE JANEIRO (CEE-RJ). Documento curricular/Seeduc: contribuições críticas de especialistas. 2019. p. 8-11. [Seminário realizado em 7 de maio de 2019]. Disponível em: <https://www.anped.org.br/sites/default/files/images/documento_ contribuicoes_criticas_dos_especialistas_1.pdf>. Acesso em: 30 nov. 2020.

CARTA do Rio de Janeiro. 24 de março de 2018. Plenária final da Conferência Estadual Popular de Educação do Rio de Janeiro Marielle Franco, realizada em 23-24 de março de 2018, na Universidade do Estado do Rio de Janeiro (Uerj). Disponível em: < https://anped.org.br/news/carta-do-rio-de-janeiro-conferenciaestadual-popular-de-educacao-rj-marielle-franco-conepe-rj>. Acesso em: 30 nov. 2020.

CONSELHO ESTADUAL DE EDUCAÇÃO DO ESTADO DO RIO DE JANEIRO (CEERJ). Deliberação CEE no 373, de 08 de outubro de 2019. Institui a implantação do documento de Orientação Curricular do Estado do Rio de Janeiro - Educação Infantil e Ensino Fundamental (DOC-RJ), definindo princípios e referências [...]. Disponível em: < http://www.cee.rj.gov.br/deliberacoes/D_2019-373.pdf>. Acesso em: 30 nov. 2020.

CONSELHO ESTADUAL DE EDUCAÇÃO DO ESTADO DO RIO DE JANEIRO (CEERJ). Documento curricular/Seeduc: contribuições críticas de especialistas. 2019. 167 p. [Seminário realizado na Universidade Federal do Estado do Rio de Janeiro (UNI-Rio), em 7 de maio de 2019]. Conteúdo: Carta de princípios para subsidiar o Documento Curricular do Estado do Rio de Janeiro; pareceres e análises por etapa, modalidade e componente curricular. Disponível em: < https://www. anped.org.br/sites/default/files/images/documento_contribuicoes_criticas_dos_ especialistas_1.pdf>. Acesso em: 30 nov. 2020.

CONSELHO ESTADUAL DE EDUCAÇÃO DO ESTADO DO RIO DE JANEIRO (CEERJ). Relatório avaliativo sobre a proposta preliminar do documento curricular do Estado do Rio de Janeiro. 2019. 176 p. [Não publicado].

GARCIA, A.; RODRIGUES, A. Existir é Ordinário: mapas de resistências nos currículos e na docência. Educação \& Realidade, Porto Alegre, v. 44, n. 3, p. 1-20, set. 2019.

LEFEBVRE, Henri. Lógica formal, lógica dialética. Rio de Janeiro: Civilização Brasileira, 1983.

METODOLOGIA de análise do Documento de Orientação Curricular e de sua homologação pelo Conselho Estadual de Educação. In: SECRETARIA DE ESTADO DE EDUCAÇÃO DO RIO DE JANEIRO (Seeduc-RJ). Documento de orientação curricular do Estado do Rio de Janeiro: educação infantil e ensino fundamental. Rio de Janeiro, 2019. p. 7-12. Disponível em: < http://undime.org.br/uploads/ documentos/phpOu2TkQ_5ddd5f2879044.pdf> Acesso em: 30 nov. 2020.

MORIN, E. Ciência com consciência. Rio de Janeiro: Bertrand Brasil, 1995.

OLIVEIRA, I. B. Currículo e processos de aprendizagemensino: políticaspráticas educacionais cotidianas. Currículo sem Fronteiras, [online], v. 13, n. 3, p. 375391, set./dez. 2013. 
REIS, G. R. F. S. Por uma outra epistemologia de formação: conversas sobre um projeto de formação de professoras no município de Queimados. 2014. 196 f. Tese (Doutorado em Educação) - Universidade do Estado do Rio de Janeiro, Rio de Janeiro, 2014

SANTOS, B. S. O fim do império cognitivo: a afirmação das epistemologias do sul. Belo Horizonte: Autêntica, 2019.

SANTOS, B. S. Pela mão de Alice: o social e o político na pós-modernidade. São Paulo: Cortez, 1995.

SECRETARIA DE ESTADO DE EDUCAÇÃO DO RIO DE JANEIRO (Seeduc-RJ). Documento de orientação curricular do Estado do Rio de Janeiro: educação infantil e ensino fundamental. Rio de Janeiro, 2019. 508 p. Disponível em: < http://undime.org.br/uploads/documentos/phpOu2TkQ_5ddd5f2879044.pdf> Acesso em: 30 nov. 2020.

SECRETARIA DE ESTADO DE EDUCAÇÃO DO RIO DE JANEIRO (Seeduc-RJ). Proposta preliminar: documento curricular do Estado do Rio de Janeiro. 2018. 456 p. [Não publicado].

Alexandra Garcia, doutora em Educação pela Universidade do Estado do Rio de Janeiro (Uerj), professora associada da Universidade do Estado do Rio de Janeiro (Uerj). Líder do Grupo de Pesquisa "Diálogos Escolas-Universidade: Processos Formativos, Currículos e Cotidianos" - CNPQ.

alegarcialima@hotmail.com

Graça Reis, doutora em Educação pela Universidade do Estado do Rio de Janeiro (Uerj), professora do Colégio de Aplicação e do Programa em Pós-Graduação da Universidade Federal do Rio de Janeiro (UFRJ). Líder do Grupo de Pesquisa "Conversas entre Professores: Alteridades e Singularidades" (ConPAS). Apoio CNPq e Faperj.

francodasilvareis@gmail.com

Patrícia Baroni, doutora em Educação pela Universidade Federal do Espírito Santo (Ufes), é professora adjunta do Departamento de Didática da Faculdade de Educação da Universidade Federal do Rio de Janeiro (UFRJ). Líder do Grupo de Pesquisa Ecologias do Narrar.

narrativasdocampo@gmail.com

Recebido em $1^{\circ}$ de julho de 2020

Aprovado em 15 de setembro 2020 